\title{
Museums Providing Opportunities for Promoting a Positive Sense of Self in the Early Years
}

\author{
${ }^{*}$ Betsy Bowers, ${ }^{* *}$ Dana Brightful, ${ }^{* * *}$ Carrie Heflin, ${ }^{* * * *}$ Anna Hindley, ${ }^{* * * * * K i m b e r l e e}$ \\ L. Kiehl, ${ }^{* * * * *}$ Erin Pruckno, ${ }^{* * * * * *}$ Cynthia Raso, ${ }^{* * * * * * * *}$ Jaime Wolfe
}

\begin{abstract}
Ethnicity and culture impact every person in both overt and subtle ways. At a very young age, children develop a sense of who they are and begin to construct meaning regarding their heritage, families, and communities. Research shows that children form 'pre-prejudices' that are set firmly in place by the age of eight. Evidence also suggests that parents and teachers need tools to provide children with the support they need to build a positive self-identity and an appreciation for others. Through collections, cultural artifacts, artistic masterpieces and everyday objects, museums are in a unique position to provide teachers and parents with important information that helps children gain insight about themselves and others from around the world.
\end{abstract}

Key Words: multicultural education, early childhood, self-identity, museums

Early childhood professionals tend to be knowledgeable about child development, educational theory and classroom management. When culturally sensitive issues arise that are related to the curriculum, early childhood educators often don't have easy access to information that will accurately inform their lessons. For this reason, it is possible that teachers find themselves inadvertently promoting stereotypes.

For example, educators at the National Museum of the American Indian (NMAI) are reminded all too often that teachers do not realize the differences between the many Native American nations and the significance of the unique characteristics that define each culture. The fact that it is not uncommon that headdress-wearing school children still visit the museum indicates a continued lack of awareness, appreciation and understanding on the part of teachers and caregivers today. Although many educators are aware of the importance of sensitively and accurately conveying information about all cultures, this example from NMAI suggests that many teachers remain unaware and ill-informed. Caregivers and educators alike are inundated with misinformation or generalizations, and often have limited information about how to approach culturally sensitive content with young children, therefore unknowingly reinforcing insensitive stereotypes. Children's literature adds to the dilemma when well-known authors present dehumanized or inaccurate representations of Native Americans. For example, the children's book Brother Eagle, Sister Sky (Harris 1993) contains a speech delivered by Chief Seattle of the Squamish tribe in the Northwestern United States. However, Susan Jeffers' illustrations are of the Plains Indians, and include fringed buckskin clothes and teepees, rather than Squamish clothing and homes. 1

In addition, educators are often unsure how to respond to young children's observations about and perceived unkindness toward people unlike themselves (Boutte and Lopez-Robertson, 2011: 335). This article explores the role that museums can play in helping young children establish a positive self-identity and an appreciation for others from three perspectives: the early childhood classroom educator, the museum itself, and the museum educator. 


\section{Background and Introduction}

The Smithsonian Early Enrichment Center (SEEC) opened 26 years ago, with its first school located in the National Museum of American History in Washington, DC. SEEC was initially created to provide full-time early care and education to nearly 50 two, three and four-yearolds of Smithsonian Institution (SI) staff. Teachers with Bachelor's degrees in Early Childhood Education developed lesson plans and implemented daily activities, which regularly used the resources of the Smithsonian Institution. Grounded in a constructivist approach to teaching and learning, SEEC educators created experiences for young children that built on what they already knew to construct new understandings. The museums were used to support children's knowledge of new concepts related to things like 'transportation,' 'real and pretend,' and 'things that change.' Approximately three years after opening its doors, SEEC became accredited by the National Association for the Education of Young Children (NAEYC), the leader in the field for recognizing high-quality care and education for children.

SEEC has since added two sites in the National Museum of Natural History and has grown to serve 135 children ranging in age from two months to six years. Today, while SEEC uses an emergent curriculum focused on in-depth exploration based on children's interests, we continue to hold presenting accurate and culturally sensitive information as part of our guiding values. Especially influenced by the work of Dewey, Vygotsky and Piaget, SEEC educators recognize the role that a child's social environment has on cognitive development. Knowledge is actively constructed, builds on prior knowledge, evolves over time and connects to real world experience. The role of the adult is to create meaningful experiences that support new perspectives. We use the museums and their myriad resources as part of the daily implementation of our curriculum from the time children enter our school as infants through to our oldest students in the Kindergarten classroom. The development of a strong sense of self and respect for others remains of utmost importance, and SEEC's educators firmly believe that museum experiences contribute to this learning in important ways.

\section{New Perspectives for Traditionally Trained Teachers}

The school first opened in October 1988, and as teachers settled into a routine and November neared, typical preschool Thanksgiving lesson plans and activities, much like those teachers had experienced in their own educational lives, were prepared and implemented with the students. SEEC parents with diverse backgrounds and credentials in fields ranging from ornithology and entomology to museum education and cultural studies realized that SEEC's preschool teachers knew how to effectively work with the children, yet perhaps were less knowledgeable about topics such as birds, bugs, Native American people and traditions, Asian culture and museum education.

Since one of SEEC's first three-year-old students was of Native American descent, the teachers quickly learned that the typical Thanksgiving arts and crafts activities that they had grown up with and had used in other schools with previous students were interpreted as culturally insensitive, even offensive. In fact, the teachers learned that eagle feathered headdresses are of great spiritual significance, symbolize honor and respect and are worn only on very special occasions by particular leaders of many Plains Indian nations. In addition, different people in Native communities from throughout the United States wear headgear that doesn't look like the commonly seen 'Plains' headdresses, and can be made from different fibers, feathers, or other natural materials, often looking much different than those most people are familiar with. These hats or headgear may be worn by women in certain communities (as opposed to most of the Plains headdresses) and often signify particular roles or other responsibilities that someone might have in their community. ${ }^{2}$

This new information was eye-opening for this group of young early childhood education professionals, and in the 1990s other educators across the country began to more thoughtfully consider sources that reinforced negative stereotypes and to present strategies that would counter potentially prejudiced messaging. Recommendations included choosing children's literature that portrayed more accurate depictions of current Native cultures, information about specific Indian nations or tribes and did not dehumanize Native Americans by presenting them as objects. ${ }^{3}$ 


\section{Continued Growth for SEEC Teachers}

In 2011, when the Smithsonian Institution's National Museum of Natural History hosted the Race: Are We So Different? exhibit, Smithsonian leadership requested that departments across the Institution use the opportunity to have conversations about the difficult topic of race. In response, a group of educators at SEEC pursued an action research project to explore how children under the age of six years old respond to cultural and racial differences in people. While the exhibit was targeted at audiences older than ten years of age, the team learned that the development of prejudice begins to form in a child's early years (Raabe and Beelmann 2011: 1716), highlighting the importance of an exhibit like Race as a teaching tool for young audiences. The project expanded on SEEC's approach to curriculum development and tied to ideas presented in The Antibias Curriculum (Sparks, 1988). The team of authors for this article grew from this 2011 action research project.

The original research project participants read articles, observed students and discussed how to use certain aspects of the Race: Are We So Different? exhibit, coupled with other tools (i.e. children's literature, toys, art activities) to support a young child's positive perspective of themself and others in their world. SEEC used this research to develop materials for the exhibit to support families with young children interested in understanding more about race, heritage and cultural diversity. In addition, SEEC educators developed and implemented training materials for SEEC faculty. These materials served as the foundation for 'Never Too Young,' a professional development workshop that addresses early learning and diversity appreciation. As SEEC trainers worked with local educators and it became apparent that teachers needed more specific information, questions arose that required more research and in-depth knowledge. This article is a result of this team exploration and serves as a starting point for SEEC's continued examination of the topic.

\section{A Definition of Multicultural Education}

In a nation with as much cultural and racial diversity as the United States, it is important that children recognize and value their heritage. At SEEC, we believe that an appreciation for one's self and others can best be achieved through a multicultural approach to education. Multicultural education works to achieve these goals - to help children with the development of identities, and build their awareness and sense of community with others. Multicultural education is at least three things: an idea, a reform movement, and a process (Banks and Banks 2007: 3). As an idea, multicultural education is the belief that all students - regardless of their race, gender, ethnicity, culture, language, social class, ability and religion - should have access to educational equality in schools. As a reform movement, multicultural education brings that belief into practice, ensuring opportunity for equity in education for all students, regardless of their background. As a process, multicultural education is the continual effort to reach goals, such as helping students develop the knowledge, competencies, and attitudes to function across cultures and communities (Banks and Banks 2007: 4). Multicultural education's scope has widened from the movement's inception in the 1970s, during which time the movement focused on race and culture. Since then, multicultural education has come to encompass ethnicity, language, social class, gender, sexual orientation, disabilities and exceptionalities and relationships to the environment (Ramsey 2004: 7).

According to the widely accepted typology established by Sleeter and Grant in 1988, multicultural education is divided into five strands, or approaches. In the first strand, education of the exceptional and culturally different, standard curricula are adapted to meet the needs of learners from different, often minority, backgrounds to improve student achievement in school and later in society. Single-group studies are curricula designed to teach about specific groups, often those underrepresented in traditional curricula. Athird approach, human relations, focuses on developing interpersonal and intergroup relationships. Fourth, and most popular with teachers and educators, multicultural education is the recognition and celebration of racial and cultural similarities and differences. In the fifth and final strand, education that is multicultural, social justice education draws attention to discrimination and hegemony and encourages critical thinking and social change (Sleeter and Grant, 2009: 198).

The different strands of multicultural education have shaped our goals for educating 
young children. Ramsey (2004; 10-12) outlined five working goals for multicultural education for young children, many of which resonate with the ways in which museums can collaborate with parents and educators. First, children need to develop strong identities with an understanding of their role and contributions across individual, community and global levels. Rather than just a sense of self or self-appreciation, multicultural education helps students develop their identity as a member of society. This sense of identity leads to the second goal, a feeling of solidarity with others. By helping students realize that the similarities and differences among people are not at odds, but rather in a continuum, children can develop an appreciation for others and feelings of understanding, empathy and care necessary to living with people in communities, from in the classroom to around the planet. These feelings and a sense of unity with all people are necessary for a third goal for children - to think critically about and address the social issues they face. To take on challenges such as access, equity, or prejudice, children need skills in critical thinking and problem solving. Instead of accepting things as they are, a child must be able to ask thoughtful, difficult questions and work with others to address the problems they see. Museums, with their exhibitions and collections from around the world, can serve as catalysts for the types of conversations and questions that are necessary for these goals to become reality.

\section{How Young Children Make Sense of Their World}

Research shows that early childhood experiences have a profound impact on a child's ability to succeed as an adult (Galinsky 2010: 4). Most early childhood educators hope to lay a foundation that builds future citizens who positively contribute to society. As children grow and develop, their brains begin to process information in different ways. From birth (and probably before birth) children are taking in information and sorting it into categories. Babies prefer to look at things that are both new and moderately complex, and by two years of age they already have the ability to classify objects. The brain is a natural categorizer - taking information in and trying to make sense of it by organizing it and putting it into specific categories. During the early childhood years, children have short attention spans and are often easily distracted. Between two and five years of age, children begin to develop the ability to focus their attention for longer time periods. In addition, they begin to be able to recognize and recall information they have seen before, as well as share this information with others. Long-term memory also develops during these years, making it more likely that children will remember information gathered during this particular time period.

Famed theorist and developmental psychologist Jean Piaget posits that children build and recognize schema by finding common traits amongst things in their environment (Piaget 1972: 82). To do this, children naturally classify and categorize the information that comes in from all their interactions. One of the ways children store information is through the use of 'scripts,' which are stories sequenced into steps that help children understand, interpret and predict what will happen in other similar situations (Moll 1990: 253). Children aged two through to five also begin to see multiple ways to solve problems and begin to be able to brainstorm different solutions.

Since the early 2000s, the United States has encountered a dramatic increase in government funded pre-school programs. Although the initiative is intended to ensure that all students enter Kindergarten with the foundational skills required to succeed in school, the result is a wide array of ideas about the most effective way to accomplish this task. While many educators, parents and policy makers value the behind-the-desk-book-learning that takes place in the elementary years, Vygotsky's sociocultural theory of learning claims play-activities to be essential to a child's experience as he or she constructs meanings of his or her environment (Bodrova 2008: 358). In addition, this phenomenon means that children often spend more time in a classroom setting than experiencing the real world. As Dewey's theory of experience proclaims, thoughtful planning based on an 'experiential continuum' takes into account the connection between educational encounters and personal experience; an important tool for SEEC educators (Dewey 1938: 46).

As children become older, their ability to focus on important information begins to develop. At this age they have also developed more capacity for processing information, allowing them 
to build connections between old and new information. During these years, children's thought processes become better organized overall.

Another skill that develops during these early years is metacognition, or the ability to think about thinking. Sometime between the ages of two and six, children begin to realize that they think with their brains (Kuhn 2000: 178). Between the ages of five and seven, children begin to grasp that they can control their brains and their thoughts. This realization is important and can be enhanced when children grow up in an environment of conversation and questions (Derman-Sparks and Ramsey 2011: 82 ).

\section{The Challenge and Related Implications}

This nation's demographic is in the midst of significant change. It is predicted that by 2018 , the majority of children in the United States will be children of color (Annie E. Casey Foundation 2014: 1). As the nation's children grow into productive adult citizens, it is critical that they have the confidence, skills and support needed to succeed in school and life. However, a recent study presents findings that suggest urgent action is required to ensure that young children develop a positive sense of self and an optimistic outlook on their future. According to the Annie E. Casey Foundation's 2014 Race for Results report, this nation's 'African-American, American Indian and Latino children face some of the biggest obstacles on the pathway to opportunity' (2014: 3). Educators will be instrumental in shifting this unfortunate trajectory.

To complicate matters further, Vygotsky's social-historical theory reminds us of the significant role that human interaction has on an individual's development (Crain 2000: 214). Research indicates that, almost from birth, children begin to identify differences between other people and themselves, but there are no hard and fast rules for how to support a child in developing a positive sense of self and an appreciation for others (Aboud 2005; Katz 2003: 897). Since sorting and categorizing is the way children make sense of the world around them, how then do educators help young children avoid stereotyping? Media and pop culture add to this challenge, as children of all ages are inundated by examples, which both reinforce and challenge what they know about gender, race and culture (King, Gloodsworth-Lugo and Lugo-Lugo 2010: 5). As a child begins to form a sense of their own identity and interact with other adults and children in an increasingly diverse society, it is difficult to know how to help that developing child effectively navigate the process.

Research shows that by the age of three, children hold stereotypes about groups of people and can express these stereotypes through words (Derman-Sparks and Ramsey 2011: 45). A common misperception is that if a child lives in an environment where stereotypes and prejudices are not overtly expressed they will not develop them. In fact, because young children do take in all that they hear and categorize the information, it is vital that they are in environments where these issues are actually discussed regularly and accurately (Boutte, Lopez-Robertson and Powers-Costello 2011: 338-41).

\section{The Parent Role}

Despite the progress this nation has made in creating more equal opportunities for all, belief systems are handed down from one generation to the next. Even as the United States commemorates the fiftieth anniversary of the Civil Rights Movement, many attest to the reality that a 'white privilege' mindset remains pervasive (Tatum 1997: 8). This challenging history influences each of our experiences and how we might parent our own children. It goes without saying that a parent's personal history and background influences how they interpret their world and, in turn, provides the groundwork for how their children will interpret their own world. How often have you overheard a parent giving misinformation about a culture, group or exhibition to a child during a visit to your museum? Although unintentional, the information shared by a parent (or the information not shared), whether through actions or words, serves as the child's foundation of truth. How then do educators outside of the family suggest to a child that their parent does not have the facts straight? These are important questions that museums should consider as they develop exhibits, create programming and provide resources that support new understandings of and appreciation for all people starting at birth. Museums also need a set of guiding values and parameters that help staff and volunteers provide consistent responses to culturally insensitive and ill-informed visitors. 


\section{The Role of Professional Educators}

Just as a parent's background informs their worldview, educators enter their professional career with their own set of unintended biases. As author/educator Candace Kuby (2003) reminds us in her book, Critical Literacy in the Early Childhood Classroom, it is an educator's life experiences that influence how each thinks about the world around them. This individual perspective could shape curricular activities and discussions with children (Kuby 2013: 57). For coursework in Early Childhood Education to be useful in teaching cultural humility and acceptance, educators must be required to reflect deeply on their own experiences, preconceptions and knowledge. Early Childhood degree programs tend to focus on developmental theory, socialization skillbuilding and teaching strategies, rather than on how to be culturally sensitive and build a positive self-identity.

Although it is rare that students and teachers together are invited to deeply and critically examine their held beliefs and experiences, a London-based school sets an effective example for consideration. Students follow a 'carefully structured process' to create self-portraits that include 'elements of their selves that the teacher and the school consider to be salient to identity (e.g. language, national origin, religion, interests and skills)' (Wells 2007: 273). The design follows a particular format that presents individual differences within a framework that emphasizes overarching similarities, suggesting that the students and teachers share common traits. By posting the children's work in a shared school space, students have a visual reminder of their own identity construct as it fits within the larger school community (Wells 2007: 274).

Understandably, educators focus their classroom experiences on familiar topics with information that is easy to access. Connections to culture are often made through familiar children's literature, prior knowledge and other easily available resources. It is difficult for teachers to provide students with culturally sensitive and accurate information, and respond appropriately to challenging inquiries and difficult issues when the resources they need are not at their fingertips. Teachers look toward easy-to-access materials to help fill this gap. This creates an opportunity for museums to inform teachers about things of which they have limited knowledge. For example, by providing on-line access to content-rich photographs, art and examples of culturally significant objects, museums can provide educators with tools that will help young children make concrete, current and real-world connections to people past, present, near and far, in ways that could spark a child's appreciation for something outside their immediate community.

In the same way that teachers must be provided with the opportunity to examine their own experiences and held beliefs, it is vital that museum professionals do the same within the walls of their respective museums. Museum professionals can easily fall into the belief that museums are welcoming to all and that all parents and teachers feel comfortable coming to visit these spaces. It must, however, be acknowledged that for some families, museums are places that are uncomfortable and may be associated with educational experiences that were less than positive as they were growing up (Acuff and Evans 2014: xiv). A person's own biases might influence how they present themself to the community (Miller \& Garran 2008: 5). Staff, volunteers and docents should be encouraged, even required, to think deeply about how their own social identity influences the visitor's experience. What values do they bring to their work in a museum and how are those values manifested in their interactions with the public? These are the types of questions that museum professionals need to be asking in order to provide the richest experience for the widest population.

In the following sections, we will examine additional roles museums might play in developing understandings of self and others for young children from three different, yet related, perspectives: the museum itself, the early childhood classroom educator, and the museum educator.

\section{Early Learning in Museums}

While museums have long recognized the potential power that they have in providing these types of experiences for the public, historically, young children have not been a target audience - and in many museums young children have not even been welcome. However, this trend has 
been reversing in recent years as more and more traditional museums are not only recognizing the importance of this audience, but are striving to welcome young children, understand their developmental needs and serve them in age-appropriate ways (Bowers, 2012: 44). The Smithsonian Institution is embracing this audience in a historically unprecedented manner. Dedicated staff, exhibition space and programming have been growing at the Smithsonian, and their work is making an impact on the field of museum education.

More evidence of the increasing recognition of the importance of early childhood education in museums can be seen at the Smithsonian's newest museum, the National Museum of African American History and Culture (NMAAHC). For perhaps the first time, a national museum that is not specifically a children's museum has identified young children as a target audience from its inception. NMAAHC is in a unique position to provide opportunities to positively influence the development of racial attitudes, cultural understanding and positive in-group and out-group identity with young children through its mission and collection. This particular museum is creating an educational framework to empower, enrich and teach young children and the adults in their lives, as well as dedicating space within its walls to provide handson opportunities to make this happen. This task is oftentimes daunting and its goals are lofty, yet NMAAHC recognizes it is in the unique position to impact the lives of young children and combat racism and prejudices starting at an early age - exactly when this work should begin.

Teaching about other cultures, races and traditions can be a daunting task. These themes are nuanced, sensitive and powerful and, thus, many shy away from them. That is where the museum can act as a resource, as well as the content expert. Traditionally when we think of the museum, we envision the painstaking research of curators and their body of work - exhibitions, catalogs, lectures. Those outlets are ever-expanding with technology, and now audiences far and wide can listen to podcasts of symposia or gallery talks, or visit a collection digitally and benefit from this expert point-of-view from their own home or classroom. That said, many teachers and parents struggle with how to take such rich content and distill it in a way that is developmentally appropriate. It is at this juncture that the museum educator becomes so pivotal. Education departments are working side-by-side with curators to create resources featuring their collections in a manner that broadens and deepens our understanding of a culture. Moreover, educators are creating spaces where children can visit and identify with cultures in a more meaningful way. For example, the diverse environment of the ImagiNATIONS space at NMAI provides children with the opportunity to explore different traditional homes, learn about the Native science behind snow-shoes, and explore Indigenous crops. In addition to these environments, classroom educators should also consider the museum as a touchstone to a cultural community. Oftentimes, museums celebrate a culture by featuring artists, performers, storytellers and even local businesses in the museum. By providing developmentally-appropriate online resources that parents and teachers can access prior to participating in a museum experience, an adult can prepare the child for building a deeper understanding of what they will experience in the museum, and asking meaningful questions that will support an appreciation for what is learned.

As more museums begin to embrace the audience of young children, their families and their teachers, we have the opportunity to help shape the ideas and understandings children have in regards to their place in the larger world. We can help provide them with factual information and expose them to varying ways of living and new ideas. By embracing this role, we can help shape not only the education of young children, but also the way they will be in the world as adults. The potential impact of everyone embracing this challenge is almost limitless.

\section{Making Connections Between Classroom and Museum}

If utilized in a thoughtful, purposeful fashion, museums can be special, safe places to further a child's understanding of different cultural constructs, as well as foster an appreciation for entities that may dwell outside of that respective child's cultural sphere. SEEC educators continuously make connections between everyday objects that are familiar to their students with the less familiar, and sometimes unfamiliar, objects of the Smithsonian's vast collection that are housed in multiple museums. A study done in an early childhood program in Canada reiterates the value of material objects when explored in the context of personal culture. After 
introducing authentic objects from the immigrant student's geographical and cultural origins, it was determined that,

we need to move our focus away from the teacher and teacher-constructed environments (props, toys, plastic furniture, etc.) towards the children as their own agents of learning, and to integrate everyday objects from their multiple worlds to act as intermediaries with the classroom' (Hennig and Kirova 2012: 226).

Embedded in Vygotsky's sociocultural theory of learning, this approach is an ongoing challenge for early childhood educators and an art that SEEC educators continue to work towards.

As students at SEEC build an appreciation for their own national heritage and that of others in their classroom, museum resources expand their understanding in important ways. For example, during a recent Kindergarten discussion, one child asked why the upcoming Monday was going to be a 'stay-at-home-day.' The teacher explained that our country celebrates Martin Luther King, Jr., a man who fought tirelessly to champion the rights of all, and to ensure that people of color were treated more equally and respectfully. One child raised her hand and said, 'My mom said that black people used to have to go to school with other black people.' This particular comment sparked a discussion about how people might see another's differences as something to fear, rather than something to recognize, respect and learn from. The teacher then used the following situation as an example:

I see that many of you are wearing the colors blue, red or pink today. Suppose I put those of you wearing these colors at two of our tables, and those of you wearing different colors at the other two tables. For snack, I might give those of you wearing blue, red or pink donuts and chocolate milk, while everyone else received only water to drink because I thought that blue, red and pink were better colors than all the rest. How might the children having water for snack feel? What about those of you having donuts and chocolate milk?

As one might expect, the children voiced that such a scenario would be 'unfair' and one child responded with, 'I would love eating the donut, but I would feel sad for my other friends.'

That afternoon, en route to a specific gallery for that day's museum visit in the National Museum of American History, SEEC's Kindergarten class happened to walk past the Greensboro lunch counter. The teacher paused her class by this culturally significant object and drew their attention back to the day's earlier discussion about the donuts-versus-water scenario. The teacher then explained the importance of this particular acquisition, detailing how four AfricanAmerican young men were refused service at a diner because of the color of their skin. Instead of immediately leaving the establishment, the young men peacefully protested the injustice by staying put in their seats. One SEEC student raised his hand and astutely stated, 'Some people think men can't marry men, but I think it's okay.' This particular child was beginning to make cross-cultural connections between different kinds of prejudice and rights.

Would the aforementioned discussion have carried as much weight without visiting the Greensboro lunch counter? Possibly. However, there is no doubt that the visit made the connection deeper, richer and more real for the students. Several weeks later, as the Kindergarten students enjoyed an afternoon on their playground, one little girl approached her teachers in tears, detailing how two other girls would not play with her because they did not approve of her hat. In between heaving sobs the child said, 'They're treating me like the lunch counter boys!' The teachers then called over the other girls involved in the altercation and had them explain their side of the situation. They stated that they wanted to play by themselves, yet by the end of the conversation, the two young girls understood that their unkind words were quite hurtful to their classmate. One of the two girls who hurled the insult cast down her eyes and professed, 'I bet she feels like I did when I couldn't eat the donut.' This little girl began to understand the power of her words, and, subsequently, empathized with the isolation of feeling 'otherized.' It bears mentioning here that each time this Kindergarten class passed by the Greensboro lunch counter following this discussion, several students would inevitably point out the object and reminisce about the important discussion in which it played a significant, meaningful role.

Museums have the power to serve as a conduit toward provoking further understanding 
of cultural constructs, which may differ from our own. For this particular Kindergarten class, the Greensboro lunch counter served as a palpable reminder of the importance of respecting those different from themselves. It is also likely that years and years from now, those same children will be reminded of that pivotal classroom discussion whenever the topic of segregation might arise in a certain context. They will remember the Greensboro lunch counter and all that it symbolizes. As adults they may share their Kindergarten experience with their own children as they visit this same counter. Museums possess the unique opportunity of providing young children with an immediate, tangible connection to a culturally significant ideal. In turn, museums begin to open the doorway toward one's own understanding of how one fits into the larger cultural fabric of the world.

Educators and parents alike may find it difficult to envision how an under-six audience will manage in the 'museum environment', and the topic has been the source of some debate and discussion. Adults can often generalize museum space as being singularly contemplative, quiet and still. The opposite comes to mind when we think of toddlers, preschoolers and Kindergarteners. As the above example indicates, when given the right framework, museums are an ideal learning space for this audience. These institutions are filled with objects and provide children the opportunity to see the 'real thing.' At this age, children are concrete learners, and therefore benefit from the experience of seeing the physical object.

\section{SEEC Classroom Application: Learning Letters}

During the preschool years, children are beginning to learn and form their letters. This particular skill is a universal theme for most classrooms, and so it is with that in mind that we often take students to the Freer Gallery of Art's Islamic galleries to visit the rotating selection of Islamic manuscripts. In our classroom prior to the museum visit, we often sit together and look at the Roman alphabet. We use the familiar 'ABC song' as an anticipatory set to pique our students' interest. We then proceed to ask them, 'Did you know that there are other alphabets different from our own?' We listen and respond to their answers, and subsequently produce the Arabic alphabet. The students are excited to see this new type of writing, so we take turns passing the alphabet around the circle. We entertain a discussion about the similarities and differences between the Arabic alphabet and our own. At this point, students are often ready to move on to a different activity, therefore we prepare to head over to the museum with our mission: to find Arabic letters.

Upon arriving at the Freer Gallery, we invite our students to use their 'looking eyes' to spy any letters from the Arabic alphabet. Shortly after setting foot in the designated gallery, we begin to hear enthusiastic statements of 'I see some, I see some!' Walking slowly, we ask children to point to the object where they see the specific letters. We might even ask them to find a word to identify the object; for example, 'Is it a plate, pitcher or vase?' We find the manuscripts and reconvene as a large group. The first thing we inquire is, "What do you see?' Again, we take time to listen to their responses and oftentimes structure our discussion around one or two of their observations. Typically, our students notice that there is writing accompanied by a picture. We return their focus back to the writing and explain that it is not merely the typical pen-on-paper writing with which they are most familiar, but a special type of writing called calligraphy. This new vocabulary word is emphasized by writing it out on paper and then displaying it in the classroom after our visit. After introducing this novel word, we ask them if they know what calligraphy is and give them a developmentally appropriate explanation - 'beautiful writing'. It is at this point that we bring out a reed pen, ink well and some parchment paper. We pass around each object, discussing its physical features. Then we ask, 'How do you think these were used?' We give children the time to respond and then, if they are not too distracted, we read them a book related to our discussion in the gallery. Back in the classroom, each child gets a turn writing with the aforementioned materials and we plan to visit the Freer Gallery again. During a subsequent visit, we will discuss how this piece of parchment is one piece of a larger book. We put the word calligraphy on the wall along with a reproduction of the manuscript page we saw. As we continue to explore this concept, we add elements to the wall, including our students' artwork. Children are introduced to new perspectives and unfamiliar cultures by first making connections to something familiar and 
recognizable; symbols, letters and words.

As these examples demonstrate, young children can be deeply thoughtful and reflective. By posing open-ended questions and facilitating a discussion, children can gain an appreciation for others that might not have been previously imagined. Much like an emergent curriculum, discussion provides a chance for a child to develop ownership and critical thinking - seeing where their own questions lead them. For younger children, there is less discussion, and questions tend to be more direct, i.e. 'Can you find an object in this gallery that you might wear on your feet?' As this next example indicates, by asking hard questions and encouraging children to make independent discoveries, we allow them to work through experiences and create their own meaning.
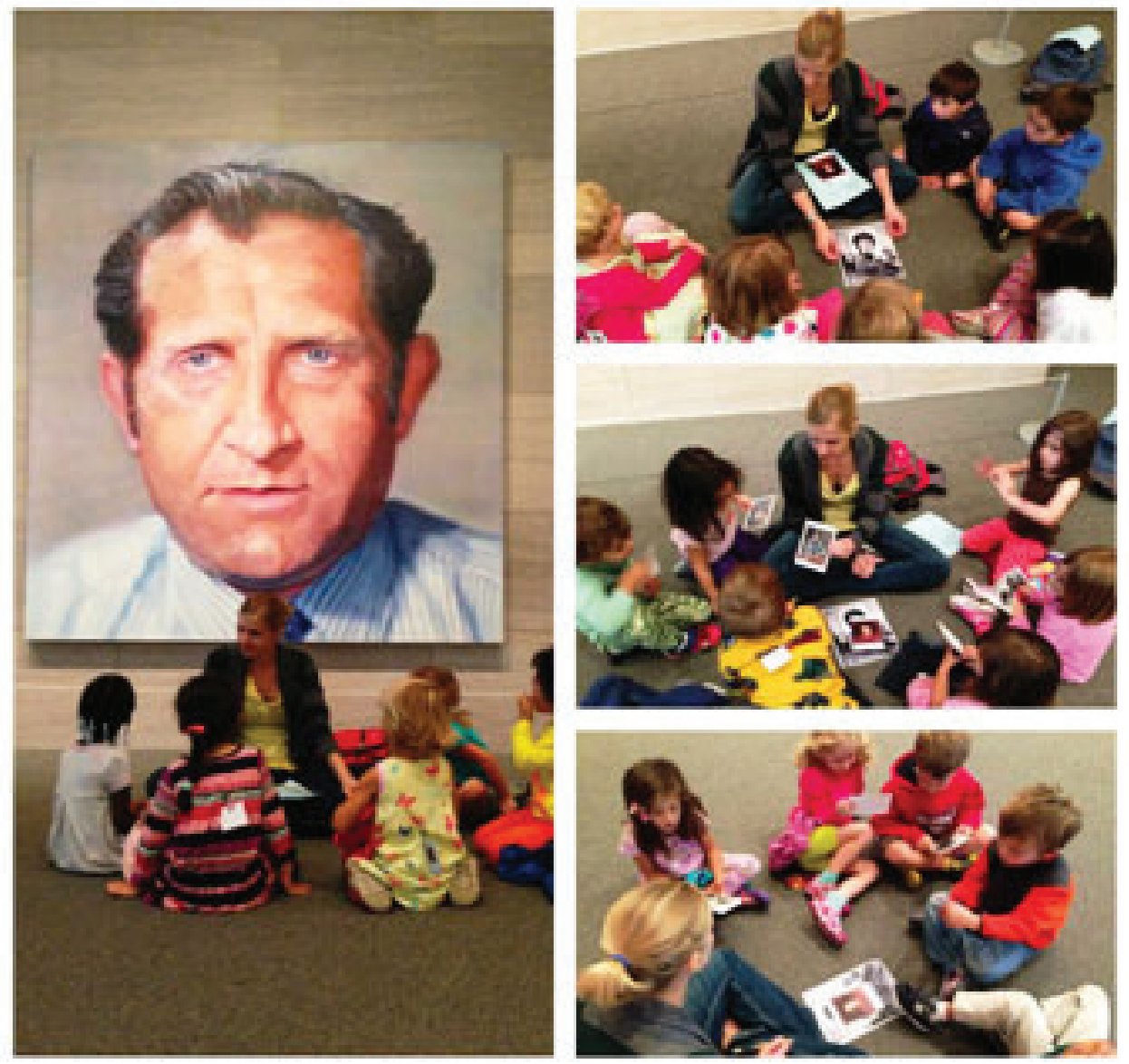

Fig 1. Portrait Discussion Photo

\section{SEEC Classroom Application: What Makes You, You?}

At the start of the school year, one of our pre-Kindergarten classrooms focused on the question: 'What makes you, you?' Our big, overarching question was, 'How do we represent ourselves?' We explored the different ways we can characterize various elements of 'who we are' by looking at different kinds of portraiture. In our classroom, the students talked about their individual physical features, such as hair and eye color, as well as why melanin makes our skin different colors. Before heading on our museum visit, we explained to our students that an artistic 
representation of a person is called a portrait. We then showed them different examples of a portrait, including one by the nineteenth century artist, James Abbott McNiell Whistler, as well as the contemporary artist, Chuck Close. The introduction of these two specific artists led to a discussion regarding the many different ways artists choose to represent the human form.

We then visited the National Portrait Gallery and sat in front of Nat, a large portrait by Chuck Close. The children shared their observations regarding the similarities and differences between the Close portrait and those smaller portraits being passed around our museum circle. The children were very interested that Close creates his large-scale portraits using fingerprints, a defining characteristic that makes each person unique. During this same visit, we incorporated a vast piece entitled Synecdoche by Byron Kim, which examines different shades of skin color in relation to identity.
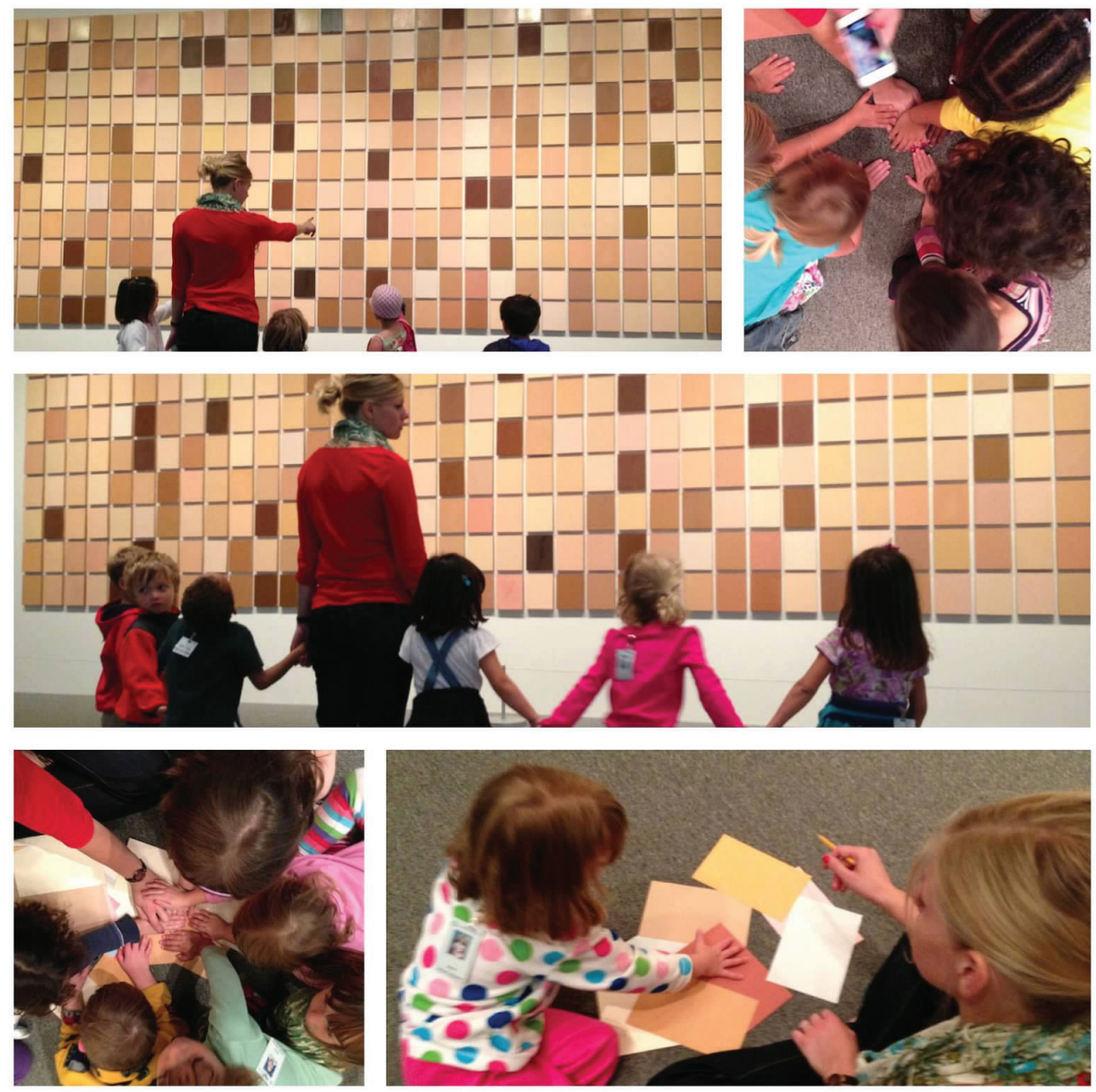

Fig 2. Skintone

This particular museum visit served to pose the question, 'What characteristics define a specific person, and how might one express their inimitable self-identity to others in the outside world?' Both Close and Kim have brought to life powerful images of both self-expression and identity using quite different forms of artistic expression. As a culmination of this particular unit, each child then had the opportunity to create their own self-portrait partially inspired by the work of Chuck Close and Byron Kim. 
The aforementioned works of art were chosen thoughtfully and specifically to illustrate how self-identity is conveyed through an artistic medium. Both pieces illustrate the importance of giving children multiple exposures to materials. Children start by discussing a concept in their classroom using inquiry-based methods, explore these ideas through kinesthetic experiences in their classrooms, then move to the museum to see an example that illustrates the concept in a different way, before finally returning to the classroom to explore the objective of the lesson more deeply with manipulative materials and purposeful play. Research has demonstrated that this use of multiple exposures to a concept aids in transfer of knowledge and flexibility of thinking (Rohrer and Taylor 2007: 481). Our museum visits create a nurturing environment for our students to make personal connections to the respective art or exhibit spaces, which serve as the focal point for any given lesson. Museums have the power to inform the thinking of young children, yet with this influence comes the responsibility of helping children make meaningful connections to their own lives.

\section{Conclusion}

Although the challenge is immense, SEEC believes that there is an important role for museums to play as we help young children develop a positive self-identity. In order to be most successful, museum professionals should step back and reflect on their own perspectives and biases and how these may affect their work and how others perceive them. Once a museum professional has considered themself, they must also consider their museum's values. Do young children see themselves represented in the space? Are young children truly welcome in the space or simply tolerated? How might the museum more effectively connect to families with young children? What tools are provided to support in-depth exploration that builds opportunities for a new appreciation for other cultures? What role, big or small, does the museum want to play in the lives of young children and their families?

Ensuring that children see themselves represented within the museum - including in the collection, in online exhibits and activities, through the staff, volunteers and in other visitors to the museum - and feel welcome in the space will allow museums to begin to have a stronger positive influence as children build their own identity and their appreciation for others. As an added benefit, the earlier children and their families begin to see themselves as museum-goers, the more likely they are to stay involved in the museum across their lifetime. Classroom teachers should recognize museums as a critical resource capable of providing accurate and developmentally appropriate information about cultures beyond their own. At SEEC, we see the power of museums in educating our children. We look forward to having more of our colleagues join us in this very important work that has the potential to shape the future of our country.

Received: 11 October 2014

Finally accepted: 6 March 2015

\section{Notes}

1 Debbie Reese, 'Teaching Young Children about Native Americans', Eric Digest 1996 http:// www.ericdigests.org/1996-4/native.htm, accessed 31 March 2015

2 Renee Gokey, personal communication, 8 March 2014.

3 Debbie Reese, 'Teaching Young Children about Native Americans', Eric Digest 1996 http:// www.ericdigests.org/1996-4/native.htm, accessed 31 March 2015

\section{References}

Aboud, F.E., (2005), 'The Development of Prejudice in Childhood and Adolescence', in J. F. Dovidio, P.S. Glick, and L.A. Rudman (eds), On the Nature of Prejudice: Fifty Years After Allport, 310-326, Malden, MA: Blackwell. 
Acuff, J.G. and Evans, L., (2014), Multiculturalism in Art Museums Today, Lanham, MD: Rowman and Littlefield.

Annie E. Casey Foundation, (2014), Race for Results Report. Baltimore, MD., http://www. aecf.org/resources/race-for-results/

Badrova, E., (2008), 'Make-believe Play Versus Academic Skills: A Vygotskian approach to Today's Dilemma of Early Childhood Education', European Early Childhood Education Research Journal, 16(3), 357-369.

Banks, C.A. and Banks, J.A., (2007), Multicultural Education: Issues and Perspectives, 6th edn. New Jersey: John Wiley and Sons.

Boutte, G.S., Lopez-Robertson, J. and Powers-Costello, E., (2011), 'Moving Beyond Colorblindness in Early Childhood Classrooms', Early Childhood Education, 39, 335342.

Bowers, B., (2012), 'A Look at Early Childhood Programming in Museums', Journal of Museum Education, 37 (1), 39-48.

Crain, W., (2000), Theories of Development: Concepts and Applications, New Jersey: Prentice Hall.

Derman-Sparks, L. and Ramsey, P. (2011), What If All the Kids Are White? Anti-Bias Multicultural Education with Young Children and Families, New York: Teachers College Press.

Hennig, K. and Kirova, A., (2012), 'The Role of Cultural Artefacts in Play as Tools to Mediate Learning in an Intercultural Preschool Programme', Contemporary Issues in Early Childhood, 13 (3), 226-241.

http://www.wwwords.co.uk/pdf/validate.asp?j=ciec\&vol=13\&issue=3\&year=2012\&article=7_ Hennig_CIEC_13_3_web.

Katz, P.A., (2003), 'Racists or Tolerant Multiculturalists? How Do They Begin?', American Psychologist, 58(11), 897-909.

King, C., Gloodsworth-Lugo, M. K. and Lugo-Lugo, C.R., (2010), Animating Difference: Race, Gender, and Sexuality in Contemporary Films for Children, Lanham, MD: Rowman \& Littlefield.

Kuby, C.R., (2013), Critical Literacy in the Early Childhood Classroom, New York: Teachers College Press.

Kuhn, D., (2000), Metacognitive Development. Current Directions in Psychological Science, 9(5) $178-181$.

Miller, J. and Garran, A.M., (2008), Racism in the United States: Implications for the Helping Professions, Belmont, CA: Brooks/Cole.

Moll, C. (ed) (1990), Vygotsky and Education: Instructional Implications and Applications of Sociohistorical Psychology, Cambridge: Cambridge University Press.

Piaget, J., (1973), The Child and Reality, New York, NY: Grossman.

Raabe, T. \& Beelman, A., (2011), 'Development of Ethnic, Racial, and National Prejudice in Childhood and Adolescence: A Multinational Meta-analysis of Age Differences', Child Development, 82(6), 1715-1737. 
Ramsey, P.G., (2004), Teaching and Learning in a Diverse World: Multicultural Education for Young Children, New York: Teachers College Press.

Rohrer, D. \& Taylor, K., (2007), 'The Shuffling of Mathematics Problems Improves Learning', Instructional Science, 35(6), 481-498.

Shaffer, S., (2011), 'Early Learning: A National Conversation', Journal of Museum Education, 37(1) 11-15.

Sleeter, C.E. and Grant, C.A., (2008), Making Choices for Multicultural Education: Five Approaches to Race, Class, and Gender, 6th edn. New Jersey: John Wiley and Sons.

Tatum, B.D., (1997), 'Why are all the black kids sitting together in the cafeteria?' and Other Conversations About Race, New York: Perseus Books Group.

Wells, K., (2007), 'Diversity Without Difference: Modeling 'the real' in the Social Aesthetic of a London Mul

*Betsy Bowers began her career at the Smithsonian Early Enrichment Center when it first opened in 1988. After spending 10 years with SEEC as an administrator, teacher and museum educator, she returned to graduate school where she received an MAT in museum education from the George Washington University. After several years as an independent consultant, she returned to SEEC to focus on expanding community based initiatives. She is a contributing author to AAM's Alliance of Spirit: Museum School Partnerships publication and the Journal of Museum Education. She is an adjunct faculty member for the George Washington University where she teaches "Museum as Learning Environment" to graduate students.

Betsy Bowers, Director

Center for Innovation in Early Learning

National Museum of Natural History

10th and Constitution Avenue, NW

Room CE-G50 MRC 184

Washington, DC 20560

Betsy Bowers

bowersb@si.edu

**Dana Brightful grew up in the Washington D.C. Metropolitan area. She spent some time at Morgan State University studying Civil Engineering when she realized her true passion was teaching young children. Since that time she has been taking classes in Early Childhood Education to enhance and sharpen her skills. Dana has worked with young children for over a decade. She has worked with toddlers, since she started at SEEC in 2005.

\author{
Dana Brightful \\ Smithsonian Early Enrichment Center \\ National Museum of Natural History \\ 10th and Constitution Avenue, NW \\ Room CE-G50 MRC 184 \\ Washington, DC 20560 \\ brightfuld@si.edu
}

${ }^{* * *}$ Carrie Heflin is a Virginia native originally from Richmond. She attended the University of Virginia where she completed her BA with a double major in Art History and Anthropology. She moved to the D.C. area two years ago when she accepted a teaching position at SEEC. While teaching she is taking courses at Northern Virginia Community College in Early Childhood Education. 
Carrie Heflin

Smithsonian Early Enrichment Center

National Museum of Natural History

10th and Constitution Avenue, NW

Room CE-G50 MRC 184

Washington, DC 20560

heflinc@si.edu

${ }^{* * * * A n n a ~ H i n d l e y ~ w o r k s ~ a t ~ t h e ~ S m i t h s o n i a n ' s ~ N a t i o n a l ~ M u s e u m ~ o f ~ A f r i c a n ~ A m e r i c a n ~ H i s t o r y ~}$ and Culture as an education specialist focusing on audiences under the age of 8 years old. She is investigating this topic in depth as the new museum determines how to best serve young audiences. She began working as a museum educator in 2003 at The Orange County Regional History Center in Orlando, Florida. She graduated with a Bachelor's Degree in history and political science from the University of Central Florida. She received her Master's Degree in Museum Studies at The George Washington University in 2012.

Anna Hindley

Anna Forgerson Hindley

Education Specialist

National Museum of African American History and Culture

Smithsonian Institution

600 Maryland Ave. SW, Suite 7001

MRC 509, P.O. Box 327012

Washington, DC 20013-7012

tel: 202.633.3571 fax: 202.633.0243

forgersona@si.edu

**** Dr. Kimberlee Kiehl is Executive Director of the Smithsonian Early Enrichment Center. She was formerly the Senior Vice President and Chief Strategy and Operations Officer at the Center of Science and Industry (COSI) in Columbus, Ohio. Prior to joining COSI, she was Associate Professor of Human Development and Family Science at The Ohio State University and Curriculum Coordinator/Director for the A. Sophie Rogers Laboratory for Child and Family Studies. Dr. Kiehl received a Bachelor of Science from SUNY Geneseo, a Master's degree from The College of St. Rose, and her Ph.D. in Curriculum and Instruction from Penn State University.

Kimberlee L. Kiehl, Executive Director

Smithsonian Early Enrichment Center

National Museum of Natural History

10th and Constitution Avenue, NW

Room CE-G50 MRC 184

Washington, DC 20560

kiehlk@si.edu

******Erin Pruckno studied anthropology and English at Skidmore College in Saratoga Springs, NY. She became the education director at the Children's Museum at Saratoga and dove into the world of museum education and early childhood, working in a variety of educational organizations since. Erin received her master's degree and graduate certificate in international education and curriculum and instruction from the George Washington University, concentrating on multicultural education, internationalizing curriculum, and early childhood. Joining SEEC in 2013, she is now a lead teacher in SEEC's preschool program.

\section{Erin Pruckno}

Smithsonian Early Enrichment Center

National Museum of Natural History

10th and Constitution Avenue, NW

Room CE-G50 MRC 184 
Washington, DC 20560

prucknoe@si.edu

*******Cynthia Raso joined SEEC as a museum educator in 2012 and a year later transitioned to her role as Public Programs Coordinator. As such, she oversees SEEC's weekend family programs and social media. Prior to joining SEEC, she founded Art Within Reach - an organization that provided classes exploring art, history, and culture for early childhood audiences. Ms. Raso worked for more than ten years at the Smithsonian's Freer and Sackler Galleries beginning in the curatorial department and later, moving into the role of educator for docents and tours. She later worked as a contractor overseeing a wide variety of public programs. Ms. Raso holds an M.A. in Art History from The George Washington University.

Cynthia Raso

Smithsonian Early Enrichment Center

National Museum of Natural History

10th and Constitution Avenue, NW

Room CE-G50 MRC 184

Washington, DC 20560

rasoc@si.edu

******** Jaime Wolfe is originally from Ohio, where she earned her Bachelor of Arts degree in English from The College of Wooster. Jaime later obtained her graduate degree in Elementary Education from the University of Pennsylvania, as well as her Master of Arts in English Literature from Middlebury College's Bread Loaf School of English.

Jaime taught first, second and third grades in the Philadelphia Public Schools. After living in Philadelphia for six years, she moved with her husband to Washington, DC, to teach Kindergarten at the Smithsonian Early Enrichment Center, a museum-based school located in the National Museum of Natural History. After five years as a Master Teacher at SEEC, Jaime has now transitioned to teaching Kindergarten for the District of Columbia Public Schools. In her teaching, she uses art, classic literature, drama and object collections to make learning come alive for her students!

Jaime Wolfe

Contact info:

Lead Kindergarten Teacher

School Without Walls at Francis Stevens Educational Campus

2425 N Street NW

Washington DC 20037

202-724-4841

jaimelwolfe@gmail.com 